\title{
"GaI": A versatile reagent for the synthetic chemist
}

\author{
Robert J. Baker and Cameron Jones* \\ Centre for Fundamental and Applied Main Group Chemistry, School of Chemistry, Cardiff \\ University, P.O. Box 912, Park Place, Cardiff, UK CF10 3TB.E-mail: Jonesca6@cardiff.ac.uk
}

Received 26th January 2005, Accepted 28th February 2005

First published as an Advance Article on the web 9th March 2005

The current renaissance in main group chemistry has been fuelled by the remarkable array of fundamentally interesting yet synthetically applicable low oxidation state p-block compounds that have appeared over the last decade. Their syntheses generally require the ready availability of low oxidation state element halide precursors. In the case of gallium this is provided by the simple to prepare reagent, "GaI", which since it was first reported in 1990, has been utilised in areas as varied as organic synthesis and gallium cluster construction. This article tracks the history of this

Robert Baker was born in 1975 in Blaenavon, South Wales. He completed his undergraduate degree at the University of Warwick and carried out his PhD studies under the supervision of Prof. P. G. Edwards at Cardiff University (1997-2000). He then worked as a postdoctoral research fellow with Professor Cameron Jones (2001-2005). In March 2005 he commenced an Alexander von Humboldt Research Fellowship at the Technische Universität München.

Cameron Jones was born in Perth, Australia in 1962. He completed both his BSc (1982) and BSc (Hons.) (1984) degrees at the University of Western Australia. From 1985-1987 he worked as a Research Officer at the University Department of Surgery at Royal Perth Hospital. His PhD degree (1989-1992) was gained from Griffith University, Brisbane, under the supervision of Professor Colin L. Raston. He then moved to a postdoctoral research fellowship (1992-1994) at Sussex University under the supervision of Professor John F. Nixon FRS. From 19941998 he held a lectureship at The University of Wales, Swansea before moving to a Readership in Inorganic Chemistry at Cardiff University. He was promoted to a Personal Chair in Inorganic Chemistry at Cardiff in 2002. Cameron was awarded the Royal Society of Chemistry's Main Group Chemistry Prize in 2004. He is the current chairman of the Royal Society of Chemistry's Main Group Chemistry Interest Forum. His research interests include the low oxidation state and hydrido chemistry of the heavier group 13 elements, and the low coordination chemistry of heavier group 15 elements. In these areas he has published more than 160 papers.

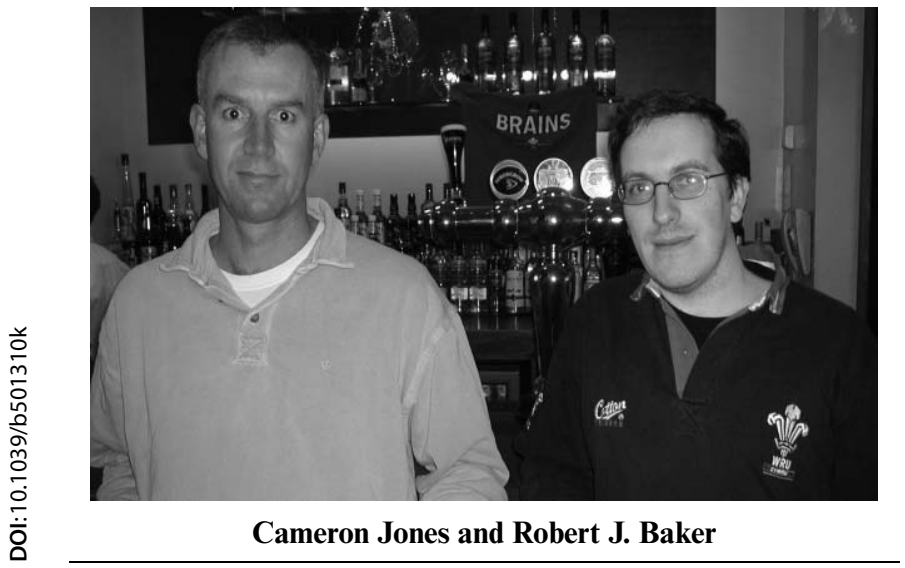

extraordinary material and highlights its synthetic diversity; hopefully allowing the reader to envisage its application to aspects of their own research fields.

\section{Introduction}

The chemistry of gallium has been dominated by compounds containing this element in the +3 oxidation state. ${ }^{1}$ The reason for this lies partly with the general assumption that compounds containing gallium in lower oxidation states, although accessible, are inherently unstable and are really only "chemical curiosities". This view neglects the enormous importance that both indium(I) and thallium(I) compounds have had to areas ranging from organic synthesis to materials chemistry. ${ }^{1}$ This is especially so for the mono-halides of these metals which are thermally stable, commercially available and make excellent synthetic precursors to indium(I) and thallium(I) alkyls, aryls, amides etc. The stability of these halides is derived from the so-called "inert pair effect" and its various causes ${ }^{2}$ which can also be used to explain the diminished stability of low oxidation state gallium (and aluminium) halides. Despite this, a variety of sub-oxidation state binary gallium halides are known, though their solidstate architectures are not always as simple as their empirical formulae might suggest. Examples here include " $\mathrm{GaX}_{2}$ ", $\mathrm{X}=$ $\mathrm{Cl}, \mathrm{Br}$ or I, which have mixed valence structures in the solid state, $\left[\mathrm{Ga}^{\mathrm{I}}\right]\left[\mathrm{Ga}^{\mathrm{II}} \mathrm{X}_{4}\right]$. Intriguingly, however, their reactions with Lewis bases (L) generally lead to "true" Ga(II) complexes which contain metal-metal bonds, $\left[(\mathrm{L}) \mathrm{X}_{2} \mathrm{Ga}-\mathrm{GaX}_{2}(\mathrm{~L})\right] .{ }^{1}$

The only crystallographically authenticated gallium(I) halide complexes have come from the group of Schnöckel who have developed a specialised reactor for the high-temperature generation of $\mathrm{GaX}$ and its subsequent co-condensation with coordinating solvents. This yields "metastable", oligomeric complexes of the type, $\left[\{\mathrm{GaX}(\mathrm{L})\}_{n}\right], \mathrm{X}=\mathrm{Cl}, \mathrm{Br}$ or $\mathrm{I} ; \mathrm{L}=$ ether, amine or phosphine. ${ }^{3}$ Even more impressively, the same reactor has been utilised to generate a series of analogous aluminium(I) halide complexes, e.g. $\left[\left\{\mathrm{AlBr}\left(\mathrm{NEt}_{3}\right)\right\}_{4}\right]$. In the past decade Schnöckel and co-workers have proved the synthetic worth of such complexes in the preparation of a remarkable array of fascinating sub-valent metal halide, amide, phosphide, silyl and alkyl cluster compounds, e.g. $\left[\mathrm{Ga}_{84}\left\{\mathrm{~N}\left(\mathrm{SiMe}_{3}\right)_{2}\right\}_{20}\right]^{4-}$, which in some cases challenge existing theories on metal-metal bonding. ${ }^{4}$ In addition, these compounds have been employed as precursors to oligomeric metal(I) alkyls and aryls (group 13 diyls), $(\mathrm{MR})_{n},{ }^{4 c}$ the monomeric units of which, e.g. :GaCp*, are fast becoming important as ligands in organometallic synthesis. ${ }^{5}$

Despite the novelty and synthetic utility of "metastable" gallium(I) (and aluminium(I)) halide complexes, the specialised technology required to generate and manipulate these species is not normally available to the preparative chemist. Fortunately, in the case of gallium an alternative is offered from the reaction of the metal with half an equivalent of diiodine in toluene. ${ }^{6}$ The resultant green precipitate, "GaI", is finding an ever increasing number of applications in organic, inorganic and organometallic syntheses, as summarised herein. 


\section{Synthesis and characterisation of "GaI"}

The first reported synthesis of GaI in 1955 by Corbett and McMullan involved heating the elements under vacuum at 350 $500{ }^{\circ} \mathrm{C}$ for 3 days. $^{7}$ The product of this reaction was washed exhaustively with benzene to leave a solid of composition $\mathrm{GaI}_{1.05}$ (mp $271{ }^{\circ} \mathrm{C}$ ) which was analysed by X-ray powder diffractometry. "GaI" was similarly prepared by Wilkinson and Worral in 1975 who heated the elements in vacuo at $250{ }^{\circ} \mathrm{C}$ for $24 \mathrm{~h} .{ }^{8}$ The product was shown to contain both $\mathrm{Ga}_{2} \mathrm{I}_{3}$ and $\mathrm{Ga}_{2} \mathrm{I}_{4}$ by Raman spectroscopy. Later, in 1982, Gerlach et al. ${ }^{9}$ revealed that the powder diffraction pattern of $\mathrm{Ga}_{2} \mathrm{I}_{3}$ was identical to that of "GaI" prepared by Corbett and McMullan. In addition, they crystallographically characterised the dark yellow $\mathrm{Ga}_{2} \mathrm{I}_{3}$ (mp $263^{\circ} \mathrm{C}$ ) and found it to exist as a mixed valence salt in the solid state, viz. $[\mathrm{Ga}]_{2}\left[\mathrm{Ga}_{2} \mathrm{I}_{6}\right]$. Moreover, they established that heating iodine and gallium under vacuum did not lead to a more reduced product than $\mathrm{Ga}_{2} \mathrm{I}_{3}$, all of which casts doubt on the original formulation of "GaI". In 1990 a new synthesis of "GaI" was reported by Green et al. ${ }^{6}$ They carried out the ultrasonically activated reaction of gallium metal and half an equivalent of diiodine in toluene at $>30{ }^{\circ} \mathrm{C}$ to give a pale green, insoluble powder, "GaI". The powder diffraction pattern of this material did not match those of the previously reported "GaI" of Corbett and McMullan or pure $\mathrm{Ga}_{2} \mathrm{I}_{3}$. It was, however, suggested that this material could be similar to "GaI" prepared by Wilkinson and Worral. This was later seemingly confirmed by Coban ${ }^{10}$ who analysed Green's "GaI" by Raman spectroscopy and found it to consist of a mixture of gallium sub-iodides, predominated by $[\mathrm{Ga}]_{2}\left[\mathrm{Ga}_{2} \mathrm{I}_{6}\right]$.

This green powder is thermally stable, very air sensitive and insoluble in non-coordinating solvents. In coordinating solvents it decomposes via disproportionation to give gallium-(II) or -
(III) iodide adducts and gallium metal (vide infra). It is relatively easy to prepare on a multigram scale in a matter of hours using commercially available ultrasonic baths. In addition, it can be stored as a toluene suspension, or as a dry solid, for months without decomposition of loss or activity. These properties make it accessible to many preparative chemists who have used it as source of $\mathrm{Ga}(\mathrm{I})$ in a variety of synthetic applications

\section{Reactivity of "GaI"}

\subsection{Reactions with Lewis bases}

The reactivity of "GaI" towards a variety of Lewis bases has been explored in some detail. This always leads to disproportionation reactions and the formation of $\mathrm{Ga}$ (II), $\mathrm{Ga}$ (III) or mixed valence products with accompanying gallium metal deposition. For example, reactions with monodentate amines, phosphines or ethers normally yield $\mathrm{Ga}$ (II) halide complexes, $\mathbf{1}$, in good yield (Scheme 1). ${ }^{6,11,12}$ It is noteworthy that this outcome contrasts with Schnöckel's aforementioned preparation of gallium(I) halide complexes, $\left[\{\mathrm{GaX}(\mathrm{L})\}_{n}\right], \mathrm{X}=\mathrm{Cl}, \mathrm{Br}$ or I, from the cocondensation of monodentate amines or phosphines with $\mathrm{GaX}^{3}$ The facile nature of the synthesis of $\mathbf{1}$ affords them significant synthetic potential in their own right. This is beginning to be examined and has led to number of results including the preparation of the first dialkylphosphide-gallium(II) complex, 2, via an unusual phosphine ligand deprotonation reaction. ${ }^{13}$

The reactions of monodentate Lewis bases with "GaI" do not always lead to $\mathrm{Ga}$ (II) iodide complexes and can give $\mathrm{Ga}$ (III) complexes, e.g. $\left[\mathrm{GaI}_{3}\left(\mathrm{PPh}_{3}\right)\right]{ }^{6}$ or mixed-valence species, e.g. 3. ${ }^{11}$ The latter complex contains two terminal Ga(II) fragments covalently bonded to a $\mathrm{Ga}(\mathrm{I})$ centre. This can perhaps be considered as an intermediate in the formation of $\left[\mathrm{Ga}_{2} \mathrm{I}_{4}\left(\mathrm{PEt}_{3}\right)_{2}\right]$

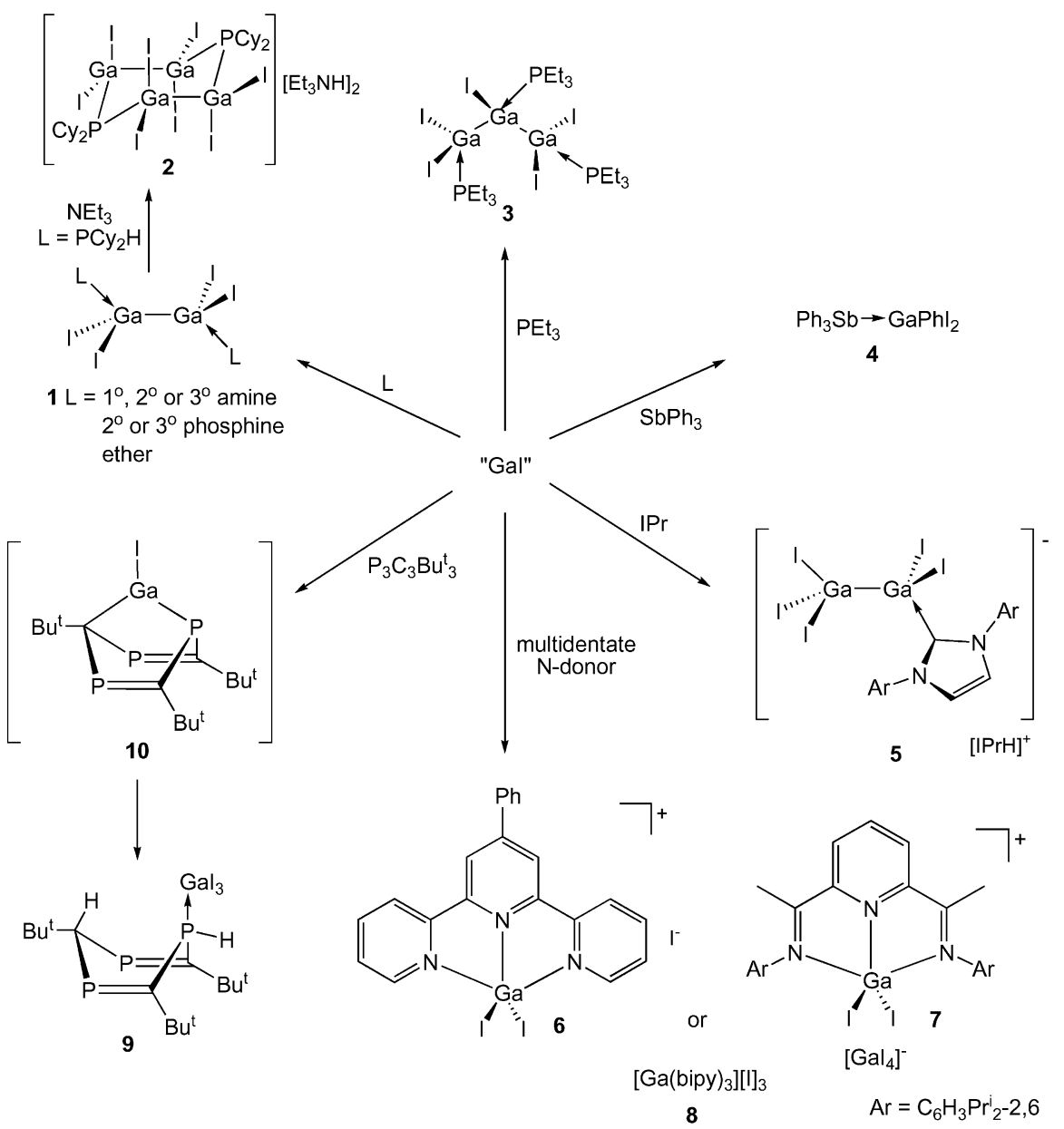

Scheme 1 Reactions of Lewis bases with "GaI". 
which was also isolated from the reaction mixture. Another interesting result has come from the treatment of "GaI" with an excess of $\mathrm{SbPh}_{3}$ which, in contrast to the formation of $\mathbf{1}$, gave complex 4, presumably via a series of disproportionation and $\mathrm{Sb}-\mathrm{C}$ insertion reactions. ${ }^{14}$ The differences here result from the relative weakness of the $\mathrm{Sb}-\mathrm{C}$ bond and highlight the reducing ability of "GaI". N-Heterocyclic carbenes (NHCs) can be thought of as highly nucleophilic Lewis bases which in the case of : $\mathrm{C}\left\{\mathrm{N}\left(\mathrm{C}_{6} \mathrm{H}_{3} \mathrm{Pr}^{\mathrm{i}}{ }_{2}-2,6\right) \mathrm{C}(\mathrm{H})\right\}_{2}, \mathrm{IPr}$, has been shown to react with "GaI" to give the salt $[\mathrm{IPrH}]\left[\mathrm{Ga}_{2} \mathrm{I}_{5}(\mathrm{IPr})\right], 5^{12}$ The imidazolium proton was presumably abstracted from the toluene solvent since the reaction is reproducible under strictly anhydrous conditions. The anion of this salt is of interest as it could have been formed by displacement of one iodide ligand from the $\left[\mathrm{Ga}_{2} \mathrm{I}_{6}\right]^{2-}$ dianion, which is thought to be a major component of "GaI". In comparison, the reaction of a similar NHC, :C $\left\{\mathrm{N}\left(\mathrm{C}_{6} \mathrm{H}_{2} \mathrm{Me}_{3}\right.\right.$ $2,4,6) \mathrm{C}(\mathrm{H})\}_{2}$, IMes, with InBr yielded the neutral In(II) complex, $\left[\mathrm{In}_{2} \mathrm{Br}_{4}(\mathrm{IMes})_{2}\right]$ via a disproportionation process. ${ }^{15}$

Unlike reactions with monodentate Lewis bases, di- and tridentate donors normally lead to $\mathrm{Ga}$ (III) products when treated with "GaI". Examples include the bipyridine (bipy), terpyridine and bis(imino)pyridine complexes, 6-8, all of which were formed in good yield. ${ }^{16}$ Although not strictly a tridentate ligand, the triphosphabenzene, 1,3,5- $\mathrm{P}_{3} \mathrm{C}_{3} \mathrm{Bu}_{3}^{\mathrm{t}}$, has been shown to react with "GaI" to give the 1,3,5-triphosphacyclohexa-1,4-diene complex, $9 .{ }^{17}$ It was proposed that in this transformation the "GaI" acted as a reducing reagent to give an intermediate [4+ 1] cycloadduct, 10, which abstracted a proton from the toluene solvent and concomitantly underwent a disproportionation reaction with excess "GaI" to give the observed product.

\subsection{Use in heterocycle formation}

One of the more useful applications "GaI" has found is in the synthesis of heterocycles containing gallium in either the $+1,+2$ or +3 oxidation state. Many of these have gone on to find their own synthetic applications. In our laboratories ${ }^{18}$ and that of Jutzi $^{19}$ the reactions of diazabutadienes, $\{\mathrm{RN}=\mathrm{C}(\mathrm{H})\}_{2}(\mathrm{DAB})$ with "GaI" have been examined. These lead to either Ga(II) or Ga(III) complexes, 11 and 12 (Scheme 2), depending on the nature of the DAB N-substituents. The mechanism of formation of $\mathbf{1 2}$ is thought to involve a combination of one electron $\mathrm{DAB}$ reduction and disproportionation reactions. In contrast, the likely initial reduction product in the formation of 11, viz. $\left[{ }^{\circ} \mathrm{GaI}\left\{\left[\mathrm{N}\left(\mathrm{Bu}^{\mathrm{t}}\right) \mathrm{C}(\mathrm{H})\right]_{2}{ }^{\bullet}\right\}\right]$, dimerises in preference to undergoing a disproportionation reaction, probably because of its relatively less bulky $\mathrm{N}$-substituents. Related to this work is the reaction of bis(2,6-diisopropylphenyl)acenaphthalene, Ar-BIAN, with "GaI" which yields 13 in a moderate yield. ${ }^{16}$ These paramagnetic species have all been characterised by EPR spectroscopy and the hyperfine couplings displayed by each indicate that the unpaired electron is primarily ligand based. In addition, several of the complexes have been studied by ENDOR spectroscopy in order to quantify the very small hyperfine couplings to the hydrogen atoms of the ligand $\mathrm{N}$-substituents. ${ }^{20}$ This has allowed an accurate map of the unpaired electron distribution over the molecules to be constructed.

An examination of the further chemistry of $\mathbf{1 1}^{\mathbf{2 1}}$ and $\mathbf{1 2}^{\mathbf{1 8}}$ has given some interesting results. Most importantly, the reduction of $12, \mathrm{R}=\mathrm{C}_{6} \mathrm{H}_{3} \operatorname{Pr}^{\mathrm{i}}{ }_{2}-2,6(\mathrm{Ar})$, with potassium metal gives good yields of the anionic $\mathrm{Ga}(\mathrm{I})$ heterocycle, 14, which is valence isoelectronic with the important $\mathrm{N}$-heterocyclic carbene class of ligand. This anion possesses a singlet lone pair at the gallium centre and, as a result, its coordination chemistry has begun to be examined. These studies are proving $\mathbf{1 4}$ to show close analogies to NHCs, especially with regard to its strongly nucleophilic nature and stabilising properties. ${ }^{22}$ Much of this work has been recently reviewed. ${ }^{23}$

"GaI" has been utilised in the preparation of another closely related $\mathrm{Ga}(\mathrm{I})$ heterocycle, $\mathbf{1 5}$, which is formed in a salt elimination reaction with $\left[\mathrm{Li}\left\{[\mathrm{N}(\mathrm{Ar}) \mathrm{C}(\mathrm{Me})]_{2} \mathrm{CH}\right\}\right](\mathrm{Li}[$ nacnac $])$ in $c a .40 \%$ yield. ${ }^{24} \mathrm{~A}$ minor product in this reaction is

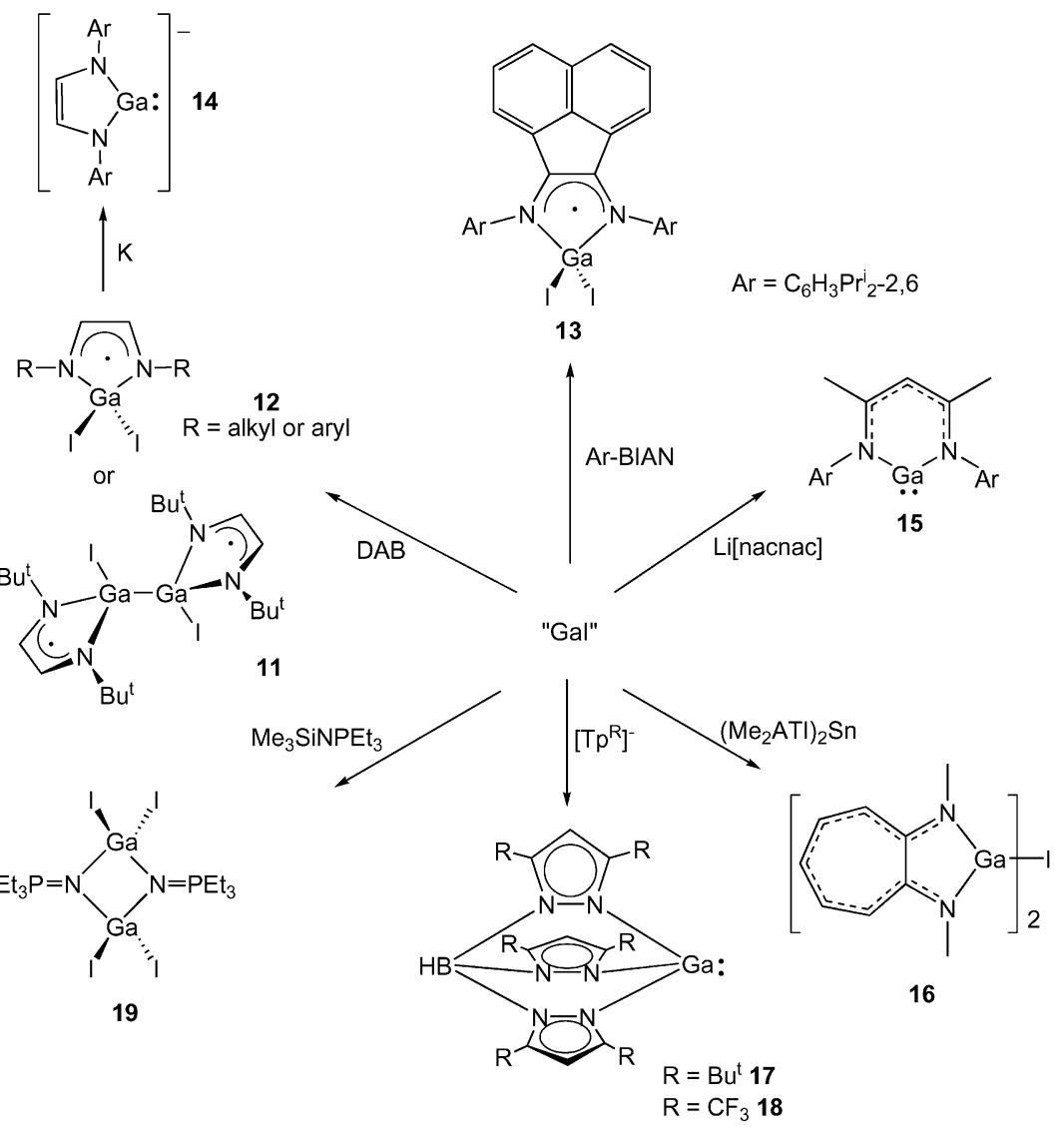

Scheme 2 Use of "GaI" in heterocycle formation. 
$\left[\mathrm{GaI}_{2}\left\{[\mathrm{~N}(\mathrm{Ar}) \mathrm{C}(\mathrm{Me})]_{2} \mathrm{CH}\right\}\right]$ (ca. $25 \%$ yield) which was isolated by fractional recrystallisation. ${ }^{25}$ Notably, this gallium(III) complex can be reduced with potassium to give $\mathbf{1 5}$. As is the case with anionic 14, the ligating properties of the neutral heterocycle, $\mathbf{1 5}$ (and its aluminium analogue), towards both main group and transition metal fragments are being studied with fascinating results. ${ }^{23}$

Related to the $\beta$-diketiminate ligand in $\mathbf{1 5}$ is the N-methyl-2(methylamino)troponiminate anion, $\left[\mathrm{Me}_{2} \mathrm{ATI}\right]^{-}$, the tin(II) salt of which, $\left[\left\{\mathrm{Me}_{2} \mathrm{ATI}\right\}_{2} \mathrm{Sn}\right]$, undergoes a redox transmetallation reaction with one equivalent of "GaI" to give the gallium(III) complex, 16, and elemental tin (Scheme 2). ${ }^{26}$ No evidence was found for the formation of the intended gallium(I) species $\left[\left\{(\mathrm{Me})_{2} \mathrm{ATI}\right\} \mathrm{Ga}\right]$, presumably due to lack of steric protection from the ligand.

Metathesis reactions between "GaI" and the tris(pyrazolyl)borate salts, $\left[\mathrm{HB}\left\{\mathrm{C}_{3} \mathrm{~N}_{2}\left(\mathrm{Bu}^{\mathrm{t}}\right)_{2}-3,5\right\}_{3}\right][\mathrm{Na}]\left(\left[\mathrm{Tp}{ }^{\mathrm{tBu}}\right] \mathrm{Na}\right)$ or $\left[\mathrm{HB}\left\{\mathrm{C}_{3} \mathrm{~N}_{2}\left(\mathrm{CF}_{3}\right)_{2}-3,5\right\}_{3}\right][\mathrm{Ag}]\left(\left[\mathrm{Tp}^{\mathrm{CF} 3}\right] \mathrm{Ag}\right)$ have been shown to give the Ga(I) complexes, $\mathbf{1 7}^{27}$ and $\mathbf{1 8},^{28}$ the former of which was revealed to be monomeric by an X-ray crystallographic study. In both reactions $\mathrm{GaI}_{3}$ complexes, viz. [( $\left.\left(\mathrm{Tp}^{\mathrm{tBu}}\right) \mathrm{Ga} \rightarrow \mathrm{GaI}_{3}\right]$ and $\left[\left(\mathrm{Tp}^{\mathrm{CF} 3}\right) \mathrm{Ga} \rightarrow \mathrm{GaI}_{3}\right]$, were isolated as by-products. These presumably arise from disproportionation of some of the "GaI" reactant during the syntheses. Both complexes were structurally characterised and found to contain rare examples of $\mathrm{Ga}(\mathrm{I}) \rightarrow \mathrm{Ga}$ (III) dative bonds. It is of note that upon coordination, the $\mathrm{Ga}-$ $\mathrm{N}$ bond lengths in 17 [2.230(5) $\AA$ ] shortened by $c a .0 .17 \AA$ to $2.05(2) \AA$ (avg.) found in the complex $\left[\left(\mathrm{Tp}^{\mathrm{tBu}}\right) \mathrm{Ga} \rightarrow \mathrm{GaI}_{3}\right]$. This observation was explained by an increase in the formal charge on the gallium(I) centre upon coordination, thus resulting in a contraction of its covalent radius. The only other heterocycle containing $\mathrm{Ga}-\mathrm{N}$ bonds to be prepared from "GaI" is the phosphoraneiminato complex, 19, which arose from a redox reaction between the gallium reagent and $\mathrm{Me}_{3} \mathrm{SiNPEt}_{3}{ }^{29}$ This was structurally characterised and found to contain a centrosymmetric $\mathrm{Ga}_{2} \mathrm{~N}_{2}$ ring with equal $\mathrm{Ga}-\mathrm{N}$ bond lengths of 1.909(4) А̊.

\subsection{Use in organogallium synthesis}

One of the earliest uses of "GaI" was in the facile syntheses of a variety of alkyl gallium diiodides, 20, via oxidative insertion reactions with alkyl iodides (Scheme 3). ${ }^{6}$ Since that time the gallium reagent has been used to prepare a range of organogallium-(I), -(II) and -(III) compounds. In general, the lower oxidation state species require kinetic stabilisation by incorporation of sterically bulky ligands. Although these can sometimes be prepared by reduction of organogallium(III) complexes, this route is often either low yielding or technically difficult. In such instances
"GaI" offers a valuable alternative to the preparative chemist. For example, Jutzi et al. have shown that the known compounds $\mathrm{Cp}^{*} \mathrm{Ga}$ and $\left(\mathrm{C}_{5} \mathrm{Me}_{4} \mathrm{Et}\right) \mathrm{Ga}, 21$, are formed in high yield by treatment of "GaI" with the potassium salt of the substituted cyclopentadienyl ligand. ${ }^{30}$ Considering the wide use of $\mathrm{Cp} * \mathrm{Ga}$ as a ligand in a variety of novel complex types, ${ }^{5}$ this represents a significant advance over the previously reported and more difficult routes to $\mathrm{Cp}^{*} \mathrm{Ga}$. These involve either alkali metal reduction of $\mathrm{Cp}^{*} \mathrm{GaI}_{2}{ }^{31}$ or salt elimination reactions between Schnöckel's metastable $\mathrm{GaCl}$ and $\mathrm{Cp}^{*}$ metallates. ${ }^{4}$ Jutzi notes, however, that in the preparation of $\mathrm{Cp}^{*} \mathrm{Ga}$, benzyl-Cp* is formed as a by-product, presumably via benzyl iodide resulting from iodination of the toluene solvent in the synthesis of the "GaI" reactant. It was revealed that this can be avoided if benzene is used as a solvent in the initial synthesis of "GaI".

Several other $\mathrm{Ga}(\mathrm{I})$ alkyls or aryls can be accessed by employing salt elimination reactions with "GaI". These include the tetrameric species, $\left[\left\{\mathrm{GaC}\left(\mathrm{SiMe}_{3}\right)_{3}\right\}_{4}\right],{ }^{4}$ and the dimeric gallium diyls, 22-24 ( $\mathrm{Ar}^{*}=\mathrm{C}_{6} \mathrm{H}_{3}\left(\mathrm{C}_{6} \mathrm{H}_{2} \mathrm{Pr}^{\mathrm{i}}{ }_{3}-2,4,6\right)_{2}$ 2,6; $\mathrm{Ar}^{\prime}=\mathrm{C}_{6} \mathrm{H}_{3}\left(\mathrm{C}_{6} \mathrm{H}_{3} \mathrm{Pr}^{\mathrm{i}}{ }_{2}-2,6\right)_{2}-2,6 ; \mathrm{Ar}^{\#}=\mathrm{C}_{6} \mathrm{H}_{3}\left(\mathrm{C}_{6} \mathrm{H}_{2} \mathrm{Pr}_{2}{ }_{2} \mathrm{Bu}^{\mathrm{t}}-\right.$ $2,6,4)_{2}-2,6 .{ }^{32,33}$ Also formed in the latter syntheses were the corresponding aryliododigallanes(4), 25-27. The crystal structure of 23 showed the molecule to have a "trans-bent" geometry with a Ga-Ga bond length of 2.6268(7) $\AA$, i.e. at the upper end of single bond interactions. This, along with cryoscopic molecular weight determinations, UV/VIS spectroscopy and further reactivity studies suggest that in solution 22-24 exist as monomeric arylgallium(I) units. The relative weakness of the solid state $\mathrm{Ga}-\mathrm{Ga}$ interaction in neutral $\mathbf{2 3}$ has important implications when it is considered that the doubly reduced form of the analogous compound 22, viz. $\mathrm{Na}_{2}\left[\mathrm{Ar}^{*} \mathrm{GaGaAr}^{*}\right]$, also possesses a trans-bent structure but has a much shorter GaGa interaction of 2.319(3) $\AA$. This was controversially described as a $\mathrm{Ga}-\mathrm{Ga}$ triple bond by Robinson et al., ${ }^{34}$ though a range of subsequent theoretical studies have implied a bond order of between 1 and $2 .{ }^{35}$ If the compound did have a triple bond, its unreduced form, 22, should have a Ga-Ga distance indicative of a double bond. This is highly unlikely given the weak $\mathrm{Ga}-\mathrm{Ga}$ interaction in $\mathbf{2 3}$.

One further novel synthetic use of "GaI" involves its reaction with the phosphavinyl Grignard reagent, $[\mathrm{CyP}=$ $\left.\mathrm{C}\left(\mathrm{Bu}^{\mathrm{t}}\right) \mathrm{MgCl}\left(\mathrm{OEt}_{2}\right)\right],{ }^{36} \mathrm{Cy}=$ cyclohexyl, to yield a terminal bis(phosphavinyl)gallium(III) complex, 28 (Scheme 3) ${ }^{37}$ The mechanism of this reaction was postulated as involving the initial formation of a $\mathrm{Ga}(\mathrm{I})$ intermediate, $\left[\mathrm{Ga}\left\{\mathrm{C}\left(\mathrm{Bu}^{\mathrm{t}}\right)=\mathrm{PCy}\right\}\right]$, which reacts with excess "GaI" to give the product via a series of redistribution and disproportionation reactions. This outcome is unusual in light of the fact that the closely related reaction of 2 equivalents of $\left[\mathrm{CyP}=\mathrm{C}\left(\mathrm{Bu}^{t}\right) \mathrm{MgCl}\left(\mathrm{OEt}_{2}\right)\right]$ with $\mathrm{GaCl}_{3}$ did not

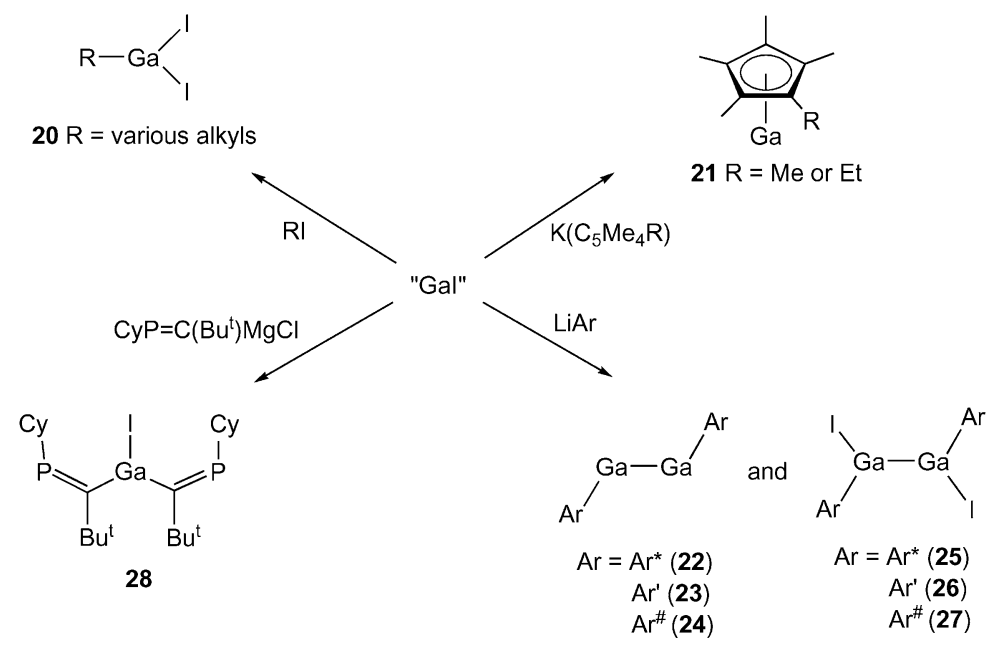

Scheme 3 Use of "GaI" in the synthesis of organogallium compounds. 


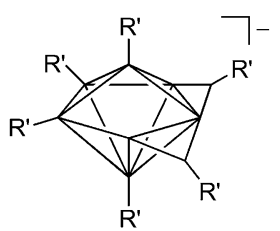

29

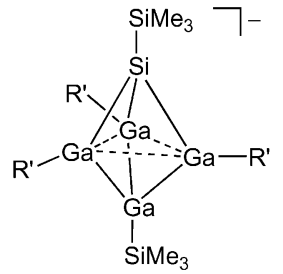

32

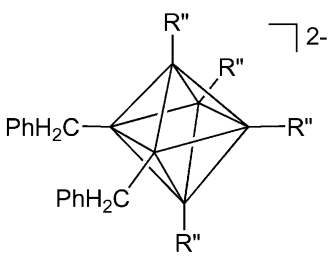

35

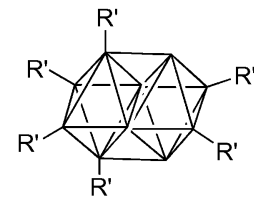

30

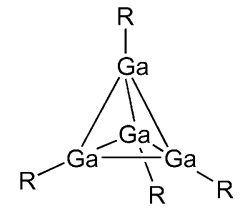

$\mathrm{R}=\mathrm{R}^{\prime}, \mathrm{R}^{\prime \prime}$ and $\mathrm{Ge}\left(\mathrm{SiMe}_{3}\right)_{3}$

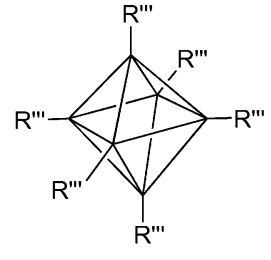

36

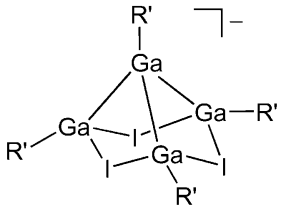

31

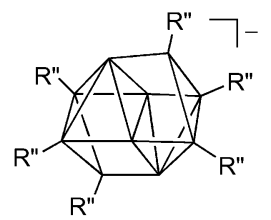

34

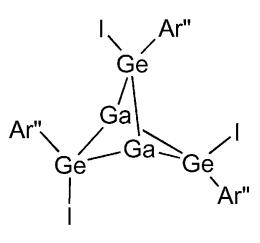

37

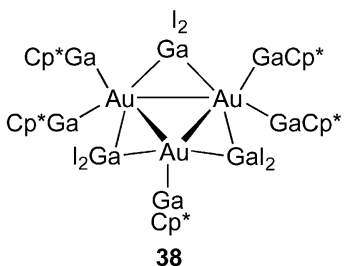

polyhedron vertex $=\mathrm{Ga}$

$\mathrm{R}^{\prime}=\mathrm{Si}\left(\mathrm{SiMe}_{3}\right)_{3}$

$\mathrm{R}^{\prime \prime}=\mathrm{SiBu}_{3}^{\mathrm{t}}$

$\mathrm{R}^{\prime \prime}=\mathrm{SiMe}\left(\mathrm{SiMe}_{3}\right)_{2}$

$\mathrm{Ar} "=\mathrm{C}_{6} \mathrm{H}_{3}\left(\mathrm{C}_{6} \mathrm{H}_{2} \mathrm{Me}_{3}-2,4,6\right)_{2}-2,6$

38

Fig. 1 Examples of gallium containing clusters prepared using "GaI".

give the chloro analogue of $\mathbf{2 8}$, though this was implicated as an intermediate in the formation of the observed phosphavinyl coupled galladiphospabicyclo[1.1.1]pentane product, $\left[\mathrm{Bu}^{t} \mathrm{C}(\mu-\right.$ $\left.\mathrm{PCy})_{2}\left\{\mu-\mathrm{GaC}\left(\mathrm{Bu}^{\mathrm{t}}\right)=\mathrm{PCy}\right\} \mathrm{CBu}^{\mathrm{t}}\right] .^{38}$

\subsection{Use in the synthesis of gallium cluster and related compounds}

Given the great success that Schnöckel has had using metastable solutions of $\mathrm{GaX}$ in the preparation of an impressive range of gallium clusters, it is not surprising that the more widely accessible reagent, "GaI", has also been exploited as a precursor in this regard. Indeed, to date this has been the most versatile synthetic use of the gallium reagent. Of the reactions described in the literature, the majority involve salt eliminations involving "GaI" and bulky silyl or germyl anions. Often, complex mixtures of decomposition or disproportionation products arise from these reactions. For example, treatment of "GaI" with $\mathrm{LiGePh}_{3}$ gives, amongst other products, the first linear trigallane anion, $\left[\left(\mathrm{Ph}_{3} \mathrm{Ge}\right)_{3} \mathrm{Ga}-\mathrm{Ga}-\mathrm{Ga}\left(\mathrm{GePh}_{3}\right)_{3}\right]^{-}$, which contains a naked central gallium centre. ${ }^{39}$

As an illustration of the versatility of "GaI" in polyhedral and sub-polyhedral cluster formation, its treatment with the bulky $\left[\mathrm{Si}\left(\mathrm{SiMe}_{3}\right)_{3}\right]^{-}$anion under various stoichiometries and conditions has given a large number of interesting compounds, most of which have been structurally characterised, e.g. 2933 (Fig. 1). ${ }^{40-43}$ Of these, $\left[\mathrm{Ga}_{9}\left\{\mathrm{Si}\left(\mathrm{SiMe}_{3}\right)_{3}\right\}_{6}\right]^{-}$29, was the first polyhedral gallium cluster with more metal atoms than substituents. ${ }^{41}$ The structure consists of a pentagonal bipyramidal core with two of the equatorial edges bridged by a $\mathrm{Ga}\left\{\mathrm{Si}\left(\mathrm{SiMe}_{3}\right)_{3}\right\}$ unit (i.e. eight framework electron pairs), as predicted by Wade-Rudolph-Mingos rules. Similarly, com- pound $\left[\mathrm{Ga}_{10}\left\{\mathrm{Si}\left(\mathrm{SiMe}_{3}\right)_{3}\right\}_{6}\right] 30,{ }^{40}$ was said to be reminiscent of a conjuncto-polyhedral cluster and to fit Cotton's definition of

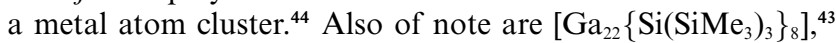
which had been previously prepared from metastable $\mathrm{GaBr},{ }^{45}$ and the "closo-silatetragallane" anion, 32, which theoretical studies suggest has weak "equatorial" Ga-Ga interactions. ${ }^{42}$

Small variations in the electronics and steric bulk of the anionic ligand in reactions with "GaI" can afford different cluster products. Examples here include $\mathbf{3 4}$ and $\mathbf{3 5}$ which incorporate the ligand $\left[\mathrm{SiBu}_{3}^{\mathrm{t}}\right]^{-}$. The presence of benzyl ligands in the latter was said to arise from deprotonation of the toluene solvent by the very basic silyl anion reactant. ${ }^{46}$ Other closely related anions that have been reacted with "GaI" are $\left[\mathrm{SiMe}\left(\mathrm{SiMe}_{3}\right)_{2}\right]^{-}$ and $\left[\mathrm{Ge}\left(\mathrm{SiMe}_{3}\right)_{3}\right]^{-}$which have given rise to clusters such as 33, 36 and $\left[\mathrm{Ga}_{22}\left\{\mathrm{Ge}\left(\mathrm{SiMe}_{3}\right)_{3}\right\}_{8}\right]$. ${ }^{46,47}$

A small number of gallium cluster and cage compounds have come from the treatment of "GaI" with reagents other than silyl or germyl anions. For example, reaction with $\mathrm{LiAr}^{\prime \prime}$, $\mathrm{Ar}^{\prime \prime}=\mathrm{C}_{6} \mathrm{H}_{3}\left(\mathrm{C}_{6} \mathrm{H}_{2} \mathrm{Me}_{3}-2,4,6\right)_{2}-2,6$, yielded a paramagnetic cluster, $\left[\mathrm{Ga}_{11} \mathrm{Ar}^{\prime \prime}{ }_{4}\right]$, which incorporates seven gallium atoms that do not carry any substituents. ${ }^{33}$ This result can be compared to the analogous preparations of the dimeric gallium diyls, 22$\mathbf{2 4}$, and suggests that in those compounds the greater steric bulk of the terphenyl ligands is required to prevent disproportionation processes and cluster formation. The $\mathrm{Ar}^{\prime \prime}$ ligand has also been utilised to stabilise a $\mathrm{Ga}_{2} \mathrm{Ge}_{3}$ cluster, 37, from the reaction of "GaI" with $\mathrm{Ar}$ " $\mathrm{GeCl}$ in which the gallium reagent is acting as a reducing reagent. ${ }^{48}$ This is the first structurally characterised example of a cluster with a $\mathrm{Ga}-\mathrm{Ge}$ framework. "GaI" has additionally been utilised as a reducing reagent (in combination with $\left.\mathrm{Cp}{ }^{*} \mathrm{Ga}\right)$ in its reaction with $\left[\mathrm{AuI}\left(\mathrm{PPh}_{3}\right)\right]^{49}$ This afforded the unusual cluster, 38, which contains the first 


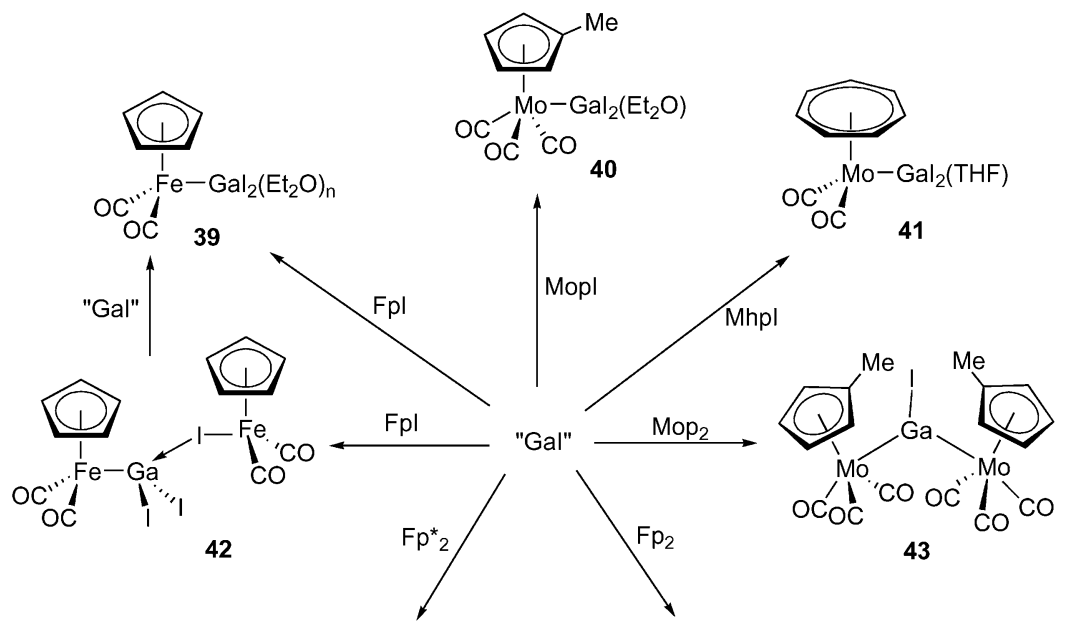

$\left[\mathrm{Cp} * \mathrm{Fe}(\mathrm{CO})_{2} \mathrm{Gal}_{2}\right]_{2}$

$[\mathrm{CpFe}(\mathrm{PhMe})]\left[\mathrm{CpFe}(\mathrm{CO})_{2} \mathrm{Gal}_{3}\right]$

45

$$
\begin{gathered}
\mathrm{Fp}=\mathrm{CpFe}(\mathrm{CO})_{2} \\
\mathrm{Fp}^{*}=\mathrm{Cp}^{*} \mathrm{Fe}(\mathrm{CO})_{2} \\
\mathrm{Mop}=\left(\mathrm{C}_{5} \mathrm{H}_{4} \mathrm{Me}\right) \mathrm{Mo}(\mathrm{CO})_{3}
\end{gathered}
$$

44

Scheme 4 Reactions of "GaI" with metal-halide and metal-metal bonds.
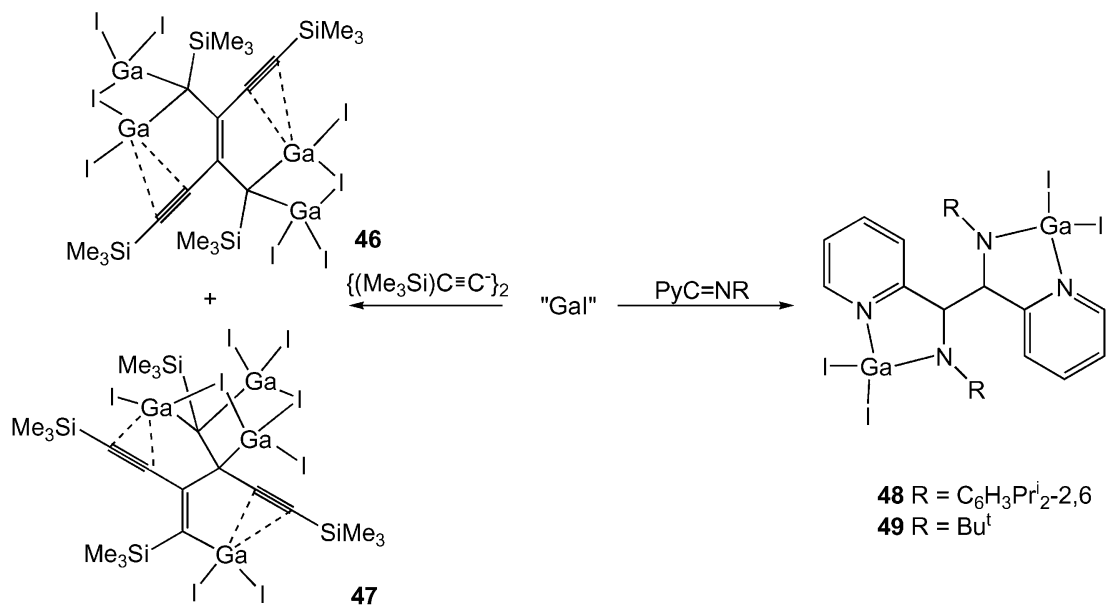

Scheme 5 The use of "GaI" as a reductant in $\mathrm{C}-\mathrm{C}$ bond forming reactions.

structurally characterised $\mathrm{Au}-\mathrm{Ga}$ bonds. Finally, it is worth mentioning the preparation of a hydridogallanate cage complex, $\left[\left\{\mathrm{KHGa}\left(\mathrm{OBu}^{\mathrm{t}}\right)\right\}_{2}\right]$, from a redox disproportionation reaction of "GaI" with $\mathrm{KOBu}^{\mathrm{t}}{ }^{43}$

\subsection{Oxidative insertion of "GaI" into metal-halide and metal-metal bonds}

There have been several reports of the oxidative insertion of "GaI" into either transition metal-halide or metal-metal bonds. The former reactions generally lead to dihalogallyl-transition metal complexes, e.g. 39-41 (Scheme 4). ${ }^{6,50}$ In some instances, e.g. 39, these are obtainable from gallium(III) halide precursors ${ }^{51}$ but routes employing "GaI" are much more facile. The stepwise nature of the pathway to $\mathbf{3 9}(n=0)$ has recently been demonstrated with the isolation of $\mathbf{4 2}$ which reacts with one equivalent of "GaI" to give the final product. ${ }^{50}$ Dihalogallyl-transition metal complexes have significant potential as precursors to a variety of $\mathrm{Ga}-\mathrm{M}$ bonded species, e.g. dialkylgallyl complexes, as has been previously demonstrated. ${ }^{6}$

Insertion of "GaI" into metal-metal bonds gives more variable results than reactions with metal halides. For example, reaction with the dimolybdenum precursor, $\left[\left\{\left(\mathrm{C}_{5} \mathrm{H}_{4} \mathrm{Me}\right) \mathrm{Mo}(\mathrm{CO})_{3}\right\}_{2}\right]$, led to the expected trimetallic system,
43. ${ }^{6}$ This is in contrast to reactions with the diiron precursors, $\left[\left\{\left(\mathrm{C}_{5} \mathrm{R}_{5}\right) \mathrm{Fe}(\mathrm{CO})_{2}\right\}_{2}\right], \mathrm{R}=\mathrm{H}$ or $\mathrm{Me}$, which give the salt, $\mathbf{4 4},{ }^{52}$ and the diiodogallyl complex, $\mathbf{4 5}$, respectively. ${ }^{50}$ The presence of water in the former reaction also led to an unusual partial oxidative hydrolysis product, $\left[\left\{\mathrm{Cp}(\mathrm{CO})_{2} \mathrm{FeGa}\right\}_{6} \mathrm{O}_{4}(\mathrm{OH})_{2} \mathrm{I}_{2}\right]$.

\subsection{Use in $\mathrm{C}-\mathrm{C}$ bond forming reactions}

Perhaps one of the least explored uses of "GaI" is as a reagent in organic synthesis. This is surprising considering the emerging application of $\mathrm{InI}$ as a reducing reagent in $\mathrm{C}-\mathrm{C}$ bond forming procedures such as Barbier allylations and Reformatsky reactions. ${ }^{53}$ The more reducing nature of "GaI" could well lead to its chemoselective use in similar transformations. An indication of this has come from the treatment of "GaI" with the 1,3diyne, $\mathrm{Me}_{3} \mathrm{SiC} \equiv \mathrm{CC} \equiv \mathrm{CSiMe}_{3}$, which affords the unusual enediyne-bis(gem-organodigallium(III)) complex as two isomeric forms, 46 and 47 (Scheme 5). ${ }^{54}$ The crystal structures of both show them to contain rare examples of a $\mathrm{Ga}(\mathrm{III})-\pi$ interactions, and the first structurally characterised gem-organodigallium fragments. The proposed mechanism for the formation of $\mathbf{4 6}$ and $\mathbf{4 7}$ involves a reduction of the diyne with "GaI" followed by $\mathrm{C}-\mathrm{C}$ coupling and disproportionation reactions. It is instructive 
that the weaker reducing agent, InI, does not react with the diyne.

In contrast to the reactions of either diazabutadienes or bis(imino)pyridines with "GaI" (which gave 7, 11 and 12), the treatment of the mono(imino)pyridines, $\mathrm{RN}=\mathrm{C}(\mathrm{H}) \mathrm{Py}(\mathrm{Py}=2$ pyridyl, $\mathrm{R}=\mathrm{C}_{6} \mathrm{H}_{3} \mathrm{Pr}^{\mathrm{i}}{ }_{2}-2,6$ or $\mathrm{Bu}^{\mathrm{t}}$ ), with the gallium reagent led to the coupled products, 48 and $49 .{ }^{16}$ As with the formation of 46 and 47 , the reaction mechanism is thought to involve a combination of imine reduction and disproportionation reactions to yield the intermediates, $\left[\mathrm{GaI}_{2}\left\{\mathrm{RNC}^{*}(\mathrm{H}) \mathrm{Py}\right\}\right]$, two equivalents of which subsequently couple. The molecular structures of 48 and 49 confirmed the $\mathrm{C}-\mathrm{C}$ bond formations and revealed that both compounds exist as their meso-isomers. The most unusual feature of these structures is that the newly formed $\mathrm{C}-\mathrm{C}$ bonds are longer than normally expected for $\mathrm{C}\left(\mathrm{sp}^{3}\right)$ $\mathrm{C}\left(\mathrm{sp}^{3}\right)$ interactions [viz. 1.603(5) and 1.581(7) $\AA$ for $\mathbf{4 8}$ and 49, respectively]. In comparison, the related reactions of iminopyridines with the weaker reductant, $\mathrm{InCl}$, were shown not to proceed via $\mathrm{C}-\mathrm{C}$ couplings and, instead, gave only $\mathrm{InCl}_{3}$ adducts, e.g. $\left[\mathrm{InCl}_{3}\left\{\eta^{2}-\mathrm{N}\left(\mathrm{C}_{6} \mathrm{H}_{3} \mathrm{Pr}_{2}{ }_{2}-2,6\right)=\mathrm{C}(\mathrm{H}) \mathrm{Py}\right\}(\mathrm{THF})\right]$, by disproportionation processes.

\section{Conclusion and future directions}

The study of compounds containing p-block elements in a low oxidation state is one of the most rapidly expanding areas of main group chemistry. The advancement of this field requires the ready availability of low oxidation state element halide precursors. In group 13 the "true" gallium(I) halide complexes of Schnöckel have allowed major advances to be made by his group, especially in cluster chemistry. However, the development of a facile synthetic route to "GaI" by Green et al. in 1990 has allowed many other synthetic chemists entry to the fascinating discipline of low oxidation state gallium chemistry. This easy to prepare and handle reagent is being employed for an ever increasing number of synthetic tasks that are either difficult or indeed impossible to carry out by other methods. Many of the products of these syntheses have themselves proved invaluable as precursors in a diversity of reactions. This will only increase into the future. Perhaps the greatest potential "GaI" holds is as a specialist reducing agent for organic transformations, an area which has only just begun to be explored. In addition, it is certain there would be no main group chemist who would not relish the opportunity to explore the synthetic possibilities that a readily accessible "Al(I) halide" reagent would offer. Whether such a reagent will appear remains to be seen.

\section{Acknowledgements}

We thank the EPSRC for funding the aspects of the work reviewed here that were carried out at Cardiff.

\section{References}

1 Chemistry of Aluminium, Gallium, Indium and Thallium, ed. A. J. Downs, Blackie Academic Press, Glasgow, 1993, ch. 1, 3, 5, 7 and 8.

2 K. G. G. Hopkins and P. G. Nelson, J. Chem. Soc., Dalton Trans., 1984, 1393, and references therein.

3 C. Dohmeier, D. Loos and H.-G. Schnöckel, Angew. Chem., Int. Ed. Engl., 1996, 35, 129, and references therein.

4 (a) A. Schnepf and H.-G. Schnöckel, Angew. Chem., Int. Ed., 2002, 41, 3533; (b) H.-G. Schnöckel and A. Schnepf, Adv. Organomet. Chem., 2001, 47, 235; (c) G. Linti and H.-G. Schnöckel, Coord. Chem. Rev., 2000, 206-207, 285, and references therein.

5 (a) C. Gemel, T. Steinke, M. Cokoja, A. Kempter and R. A. Fischer, Eur. J. Inorg. Chem., 2004, 4161; (b) R. A. Fischer and J. Weiss, Angew. Chem., Int. Ed., 1999, 38, 2830, and references therein.

6 M. L. H. Green, P. Mountford, G. J. Smout and S. R. Speel, Polyhedron, 1990, 9, 2763.
7 J. D. Corbett and R. K. McMullan, J. Am. Chem. Soc., 1955, 77, 4217; see also: J. R. Chadwick, A. W. Atkinson and B. G. Huckstepp, J. Inorg. Nucl. Chem., 1966, 28, 1021.

8 M. Wilkinson and I. J. Worrall, J. Organomet. Chem., 1975, 93, 39.

9 C. Gerlach, W. Hönle and A. Simon, Z. Anorg. Allg. Chem., 1982, 486, 7.

10 S. Coban, Diplomarbeit, Universität Karlsruhe, 1999.

11 A. Schnepf, C. Doriat, E. Möllhausen and H. Schnöckel, Chem. Commun., 1997, 2111.

12 R. J. Baker, H. Bettentrup and C. Jones, Eur. J. Inorg. Chem., 2003, 2446.

13 R. J. Baker, H. Bettentrup and C. Jones, Inorg. Chem. Commun., 2004, 7, 1289.

14 C. Jones, C. Schulten and A. Stasch, Main Group Met. Chem., in press.

15 R. J. Baker, R. D. Farley, C. Jones, M. Kloth and D. M. Murphy, Chem. Commun., 2002, 1196.

16 R. J. Baker, C. Jones, M. Kloth and D. P. Mills, New. J. Chem., 2004, 28, 207.

17 C. Jones and M. Waugh, Dalton Trans., 2004, 1971

18 R. J. Baker, R. D. Farley, C. Jones, M. Kloth and D. M. Murphy, J. Chem. Soc., Dalton Trans., 2002, 3844. For an alternative synthesis of a related anionic $\mathrm{Ga}$ (I) heterocycle, see: E. S. Schmidt, A. Jockisch and H. Schmidbaur, J. Am. Chem. Soc., 1999, 121, 9758; E. S. Schmidt, A. Schier and H. Schmidbaur, J. Chem. Soc., Dalton Trans., 2001, 121, 505

19 T. Pott, P. Jutzi, W. Kaim, W. W. Schoeller, B. Neumann, A. Stammler, H.-G. Stammler and M. Wanner, Organometallics, 2002, 21, 3169.

20 R. J. Baker, R. D. Farley, C. Jones, D. P. Mills, M. Kloth and D. M. Murphy, Chem. Eur. J., in press.

21 K. L. Antcliff, R. J. Baker, C. Jones, D. M. Murphy and R. P. Rose, Inorg. Chem., in press.

22 (a) R. J. Baker, C. Jones and J. A. Platts, Dalton Trans., 2003, 3673; (b) R. J. Baker, C. Jones and J. A. Platts, J. Am. Chem. Soc., 2003, 125, 10534; (c) R. J. Baker, C. Jones, M. Kloth and J. A. Platts, Angew. Chem., Int. Ed., 2003, 43, 2660; (d) R. J. Baker, C. Jones, M. Kloth and J. A. Platts, Organometallics, 2004, 23, 4811; (e) R. J. Baker, C. Jones and D. M. Murphy, Chem. Commun., 2005, 1339.

23 R. J. Baker and C. Jones, Coord. Chem. Rev., in press.

24 N. J. Hardman, B. E. Eichler and P. P. Power, Chem. Commun., 2000, 1991.

25 M. Stender, B. E. Eichler, N. J. Hardman, P. P. Power, J. Prust, M. Noltemeyer and H. W. Roesky, Inorg. Chem., 2001, 40, 2794.

26 H. V. R. Dias and W. Jin, Inorg. Chem., 1996, 35, 6546.

27 M. C. Kuchta, J. B. Bonanno and G. Parkin, J. Am. Chem. Soc., 1996, 118, 10914.

28 H. V. R. Dias and W. Jin, Inorg. Chem., 2000, 39, 815.

29 S. Anfang, J. Grebe, M. Möhlen, B. Neumüller, N. Faza, W. Massa, J. Magull and K. Dehnicke, Z. Anorg. Allg. Chem., 1999, 625, 1395

30 P. Jutzi and L. O. Schebaum, J. Organomet. Chem., 2002, 654, 176.

31 P. Jutzi, B. Neumann, L. O. Schebaum, A. Stammler and H.-G. Stammler, Organometallics, 1999, 18, 4462.

32 N. J. Hardman, R. J. Wright, A. D. Phillips and P. P. Power, Angew. Chem., Int. Ed., 2002, 41, 2843.

33 N. J. Hardman, R. J. Wright, A. D. Phillips and P. P. Power, J. Am. Chem. Soc., 2003, 125, 2667.

34 J. Su, X.-W. Li, C. Crittendon and G. H. Robinson, J. Am. Chem. Soc., 1998, 120, 3773.

35 R. Ponec, G. Yuzhakov, X. Gironés and G. Frenking, Organometallics, 2004, 123, 1790, and references therein.

36 D. E. Hibbs, C. Jones and A. F. Richards, J. Chem. Soc., Dalton Trans., 1999, 3531.

37 S. Aldridge, C. Jones, P. C. Junk, A. F. Richards and M. Waugh, J. Organomet. Chem., 2003, 665, 127.

38 C. Jones and A. F. Richards, J. Organomet. Chem., 2001, 629, 109.

39 G. Linti, A. Rodig and W. Köstler, Z. Anorg. Allg. Chem., 2001, 627, 1465.

40 M. Kehrwald, W. Köstlel, A. Rodig, G. Linti, T. Blank and N. Wiberg, Organometallics, 2001, 20, 860.

41 W. Köstler and G. Linti, Angew. Chem., Int. Ed., 1997, 36, 2644.

42 G. Linti, W. Köstler, H. Piotrowski and A. Rodig, Angew. Chem., Int. Ed., 1998, 37, 2209.

43 G. Linti, S. Coban, A. Rodig and N. Sandholzer, Z. Anorg. Allg. Chem., 2003, 629, 1329.

44 F. A. Cotton, Rev. Chem. Soc., 1996, 389.

45 A. Schnepf, E. Weckert, G. Linti and H. Schnöckel, Angew. Chem., Int. Ed., 1999, 38, 3381. 
46 G. Linti, S. Coban and D. Dutta, Z. Anorg. Allg. Chem., 2004, 630, 319.

47 G. Linti and A. Rodig, Chem. Commun., 2000, 127

48 A. F. Richards, M. Brynda and P. P. Power, Organometallics, 2004, 23, 4009.

49 U. Anandhi and P. R. Sharp, Angew. Chem., Int. Ed., 2004, 43, 6128.

50 N. R. Bunn, S. Aldridge, D. L. Kays, N. D. Coombs, L. L. Ooi, S. J. Coles and M. B. Hursthouse, Organometallics, submitted.
51 A. S. Borovik, S. G. Bott and A. R. Barron, Organometallics, 1999 , 18, 2668.

52 G. Linti, G. Li and H. Pritzkow, J. Organomet. Chem., 2001, 626, 82.

53 (a) B. C. Ranu, Eur. J. Org. Chem., 2000, 2347; (b) K. K. Chauhan and C. G. Frost, J. Chem. Soc., Perkin Trans. 1, 2000, 3015, and references therein.

54 R. J. Baker and C. Jones, Chem. Commun., 2003, 390. 